\title{
Alternativas para a catação química de touceiras de capim-colonião e capim- braquiária em cana-soca ${ }^{1}$
}

\author{
Alternatives to chemical scavenging of clumps of guinea grass and signal grass \\ clumps in sugarcane ratoon
}

Edvaldo Barbosa de Melo ${ }^{2}$; André Augusto Pazinato da Silva ${ }^{2}$; Antonio Mendes de Oliveira $\mathrm{Neto}^{3}$; Naiara Guerra ${ }^{3}$; Cesar Crispim Vilar ${ }^{3}$; Eduardo Leonel Bottega ${ }^{4}$; Cleber Daniel de Goes Maciel $^{5}$

Resumo - Nas regiões canavieiras do Estado do Paraná, o Panicum maximum (capim-colonião) e a Brachiaria decumbens (capim-braquiária) destacam-se como plantas daninhas de difícil controle e que comprometem a vida útil do canavial. Nesta pesquisa objetivou-se avaliar alternativas para a catação química de touceiras de $P$. maximum e $B$. decumbens na cultura da cana-de-açúcar. Para isso, foram realizados dois experimentos de campo, em delineamento de blocos ao acaso com quatro repetições no primeiro experimento e cinco para o segundo. No primeiro foram avaliados os herbicidas hexazinone e diuron+hexazinone nas concentrações de 0 ; $10 ; 11,7 ; 13,3 ; 15$ e $16,7 \%$. No segundo utilizou-se o isoxaflutole nas concentrações $0 ; 1,5 ; 3,0$ e $4,5 \%$. As avaliações visuais de controle foram realizadas aos 4, 10, 20 e 30 dias após a aplicação dos tratamentos. Os herbicidas diuron + hexazinone e hexazinone foram eficientes no controle de $P$. maximum e $B$. decumbens a partir da concentração de $10 \%$. Em relação ao isoxaflutole, foi necessária uma concentração mínima de 4,8 e 4,2\% para se obter a máxima eficiência de controle das rebrotas de $P$. maximum e $B$. decumbens, respectivamente.

Palavras-chaves: Brachiaria decumbens, herbicidas, Panicum maximum, Saccharum spp.

\begin{abstract}
In sugarcane areas of Parana State, Panicum maximum (guinea grass) and Brachiaria decumbens (signal grass) stand out as weeds with difficult control and may compromise the useful period sugar cane crop. This research aimed to evaluate alternatives to chemical scavenging of $P$. maximum and $B$. decumbens clumps in sugar cane crop. This way, two experiments were conducted in field conditions by using a complete randomized block design with four replications for the first and five for the second one. In the first experiment, hexazinone and diuron + hexazinone herbicides were evaluated at $0,10,11.7,13.3,15$ and $16.7 \%$ concentrations. In the second one, isoxaflutole herbicide was used at 0, 1.5, 3.0 and $4.5 \%$

\footnotetext{
${ }^{1}$ Recebido para publicação em 06/01/2014 e aceito em 12/03/2014.

2 Discente do curso de Agronomia da Faculdade Integrado de Campo Mourão, Campo Mourão - PR. Endereço: Rodovia BR 158, KM 207, CEP: 87300-970. E-mail: <edvaldomelo.bm@gmail.com>.

${ }^{3}$ Docente do curso de Agronomia da Faculdade Integrado de Campo Mourão, Campo Mourão - PR. Endereço: Rodovia BR 158, KM 207, CEP: 87300-970. E-mail: 〈am.oliveiraneto@gmail.com〉; naiaraguerra.ng@ gmail.com>; <cesarcvilar@gmail.com>.

${ }^{4}$ Docente do curso de Agronomia da Universidade Federal de Santa Catarina, Campus Curitibanos - SC. E-mail: <eduardo.bottega@ufsc.br>.

${ }^{5}$ Docente do curso de Agronomia da Universidade Estadual do Centro-Oeste (Unicentro), Campus Guarapuava - PR.

E-mail: <macielconsultoria@hotmail.com>.
} 
concentrations. Visual control evaluations were performed at 4, 10, 20 and 30 days after treatments application. Diuron + hexazinone and hexazinone herbicides were effective in controlling $P$. maximum and $B$. decumbens at $10 \%$ concentration. Regarding to isoxaflutole, it was necessary a minimum concentration of 4.8 and $4.2 \%$ for maximum efficiency control of $P$. maximum and $B$. decumbens sprouting, respectively.

Keywords: Brachiaria decumbens, herbicides, Panicum maximum, Sacharum spp.

A cana-de-açúcar pertence à família Poaceae, gênero Saccharum, possuindo várias espécies, sendo que as variedades cultivadas atualmente são híbridas (Dinardo-Miranda et al., 2008). No Brasil, a situação atual do setor sucroenergético é caracterizada pela busca constante de melhorias na capacidade produtiva dos canaviais, visando incremento na produção de matéria prima para atender a crescente demanda do mercado consumidor por etanol, açúcar e produção de energia elétrica por fontes renováveis (Christoffoleti et al., 2011).

A presença de plantas daninhas no canavial é um dos fatores que compromete a produção da cana-de-açúcar. Estas espécies interferem no desenvolvimento da cultura devido à competição pelos fatores de produção essenciais, que normalmente estão presentes em quantidade insuficientes para atender as plantas cultivadas e a comunidade infestante. Dentre esses fatores podemos destacar água, luz, gás carbônico, nutrientes e espaço (Pitelli, 1985).

$\mathrm{Na}$ cultura da cana-de-açúcar, as espécies Brachiaria decumbens (capimbraquiária) e Panicum maximum (capimcolonião) têm afetado seriamente a sua produção. Ambas espécies são perenes e pertencentes à família poaceae, na qual são caracterizadas pela sua agressividade, alta capacidade de adaptação a solos de baixa fertilidade e a várias condições climáticas, o que reduz a diversidade de espécies no ambiente em que elas se desenvolvem (Galli \& Montezuma, 2005; Lorenzi, 2008).

Nas regiões canavieiras do Estado do Paraná, o capim-braquiária e o capim-colonião destacam-se como plantas daninhas de difícil controle e que comprometem a vida útil do canavial. A maior dificuldade no manejo destas espécies consiste no controle das plantas oriundas de partes vegetativas (rebrotas), já que a grande maioria dos herbicidas utilizados em cana-de-açúcar é aplicada em pré-emergência, para controlar plantas oriundas de sementes.

O controle de plantas daninhas por meio de herbicidas depende da seleção de produtos eficazes e seletivos (Bhowmik \& Neal, 1995). Para um controle químico eficaz é necessário que o produto aplicado, em pré ou pós-emergência, permaneça ativo no período crítico de prevenção da interferência, o que para a cana-de-açúcar tem sido em média entre 70 e 140 dias após a emergência da cultura (Mascarenhas et al., 1995; Kuva et al., 2001, 2003).

No entanto, nem sempre é possível controlar totalmente as plantas daninhas por meio da aplicação em área total, sendo necessária a utilização de outras medidas para controlar as plantas que sobreviveram a esta aplicação. Para isto, pode-se utilizar da "catação química dirigida" ou "repasse", que consiste no uso de herbicidas aplicados após o controle químico realizado em área total, utilizando de máquinas costais ou tratorizadas. A catação química das plantas daninhas perenizadas é comumente realizada com a finalidade de aumentar a vida útil do canavial e evitar a disseminação de espécies de difícil controle para os talhões adjacentes. Além disso, esta operação tem ganhado importância com a adoção da colheita mecanizada, facilitando o deslocamento das máquinas e a limpeza do material colhido (Procópio et al., 2008; Rodrigues et al., 2011). 
Entre os herbicidas que podem ser utilizados nesta modalidade, cita-se o diuron e hexazinone que são inibidores do fotossistema II (FS2), os quais são absorvidos predominantemente via radicular, sendo sua translocação via xilema, apesar do hexazinone em menor intensidade também ser translocado via floema. Outro herbicida também utilizado em operação de catação química é o isoxaflutole. Este produto atua na inibição da síntese de carotenoides, causando paralisação na síntese destes pigmentos, levando ao surgimento de sintomas característicos de "branqueamento" de tecidos desenvolvidos após a aplicação em espécies suscetíveis, seguido de paralisação de crescimento e necrose (Pallet et al., 1998).

Esse trabalho teve como objetivo avaliar a eficiência de controle em $P$. maximum e $B$. decumbens, oriundas de touceira, após a aplicação dirigida dos herbicidas diuron + hexazinone, hexazinone e isoxaflutole em diferentes concentrações.

Dois experimentos foram realizados na fazenda Nossa Senhora das Graças, localizada no município de Tapejara/PR, durante o período compreendido entre outubro de 2012 e março de 2013. Os experimentos foram implantados em solo de textura arenosa (60 g $\mathrm{kg}^{-1}$ de argila), classificado como Argissolo Vermelho Amarelo (Embrapa, 2006).

A classificação climática da região é tropical mesotérmico, úmido, com chuvas de verão e de outono (Cfa). Os dados médios mensais de temperatura e precipitação do período experimental foram obtidos pela estação meteorológica da Usina Santa Terezinha, a qual se encontrava a $2000 \mathrm{~m}$ de distância da área experimental (Figura 1).

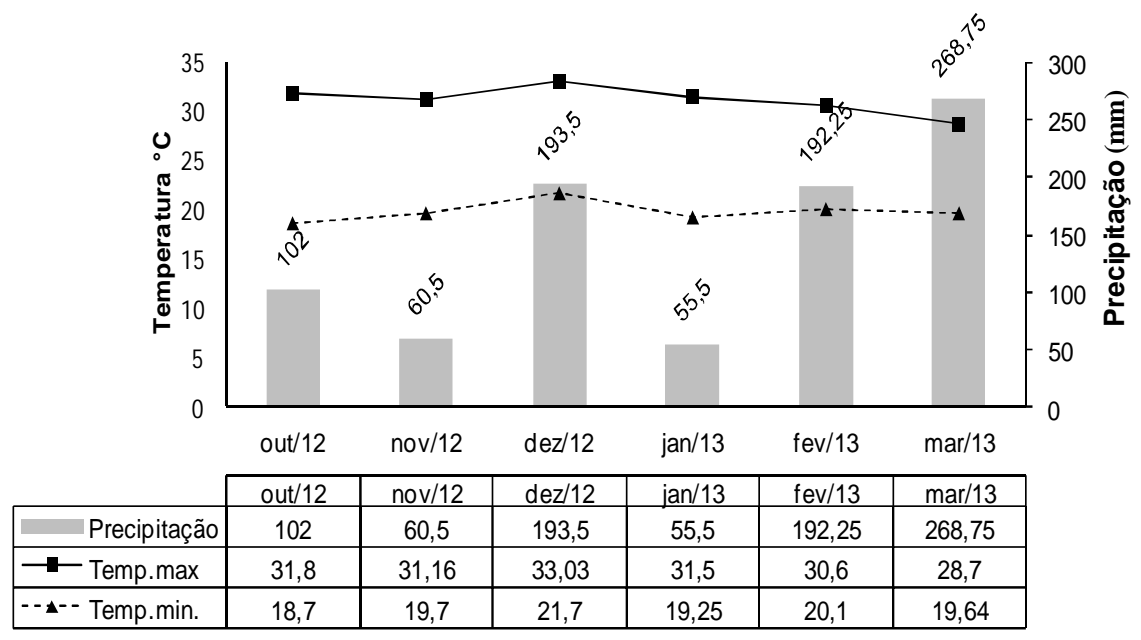

Figura 1. Temperatura $\left({ }^{\circ} \mathrm{C}\right)$ e precipitação $(\mathrm{mm})$ médias de Outubro de 2012 a Março de 2013. Tapejara, PR, 2012/2013.

No primeiro experimento, adotou-se o delineamento em blocos ao acaso, arranjados em esquema fatorial $2 \times 6$, com quatro repetições. O primeiro fator foi constituído pelos herbicidas diuron + hexazinone $\mathrm{e}$ hexazinone, e o segundo fator representado por seis concentrações de cada herbicida $(0,0 ; 10,0$;
11,$7 ; 13,3 ; 15,0$ e $16,7 \%$ de massa do produto comercial sobre volume de água). No segundo experimento utilizou-se o delineamento em blocos casualizados, com quatro tratamentos e cinco repetições. Os tratamentos avaliados consistiram de diferentes concentrações do herbicida isoxaflutole $(0,0 ; 1,7 ; 3,3$ e $5,0 \%$ da 
massa do produto comercial sobre o volume de água).

A localização do experimento estava-se com alta infestação de $B$. decumbens e $P$. maximum. Estas plantas apresentavam-se no estágio de pleno desenvolvimento vegetativo, antecendendo o florescimento e estabelecidas de forma muito agressiva, uma vez que se tratava de um canavial com a variedade RB 86 7515 em condição quarto corte, disposta em espaçamento $1,10 \mathrm{~m}$ e que não havia sido realizada nenhuma operação de adubação.

As aplicações foram realizadas em 28/10/2012, utilizando-se pulverizador pressurizado a ar comprimido, sendo que em média, foram utilizadas 40 touceiras de cada espécie invasora por unidade experimental. A pulverização foi efetuada com $30 \mathrm{~mL}$ de solução por planta, atingindo o centro da touceira e com escorrimento para o solo, a fim de que todas as touceiras recebessem o mesmo volume de aplicação.

As condições climáticas no momento da aplicação foram de céu aberto, solo úmido, umidade relativa do ar de $75 \%$, temperatura média do ar de $24^{\circ} \mathrm{C}$ e a velocidade do vento de $6,5 \mathrm{~km} \mathrm{~h}^{-1}$, condições essas adequadas para aplicação de herbicidas nessa modalidade.

As avaliações de eficiência de controle de capim-colonião e capim-braquiária foram realizadas visualmente aos 4, 10, 20 e 30 dias após aplicação (DAA) dos tratamentos. Para este procedimento utilizou-se a escala percentual proposta pela SBCPD (1995), onde a nota $0 \%$ representa nenhum controle e $100 \%$ à morte das plantas. Aos 110 DAA realizou-se a avaliação de porcentagem de rebrote das touceiras de capim-colonião e capimbraquiária.

Os dados obtidos no primeiro experimento foram submetidos à análise de variância pelo teste $\mathrm{F}$ e as médias foram comparadas pelo teste de Scott-Knott, a 5\% de probabilidade. Já os dados do segundo experimento foram submetidos à análise de variância pelo teste $\mathrm{F}$ e, posteriormente, foram ajustadas curvas de dose-resposta, através da análise de regressão, seguindo o modelo linear, a 5\% de probabilidade. Para ambas as análises utilizou-se o programa estatístico Sisvar ${ }^{\circledR}$ (Ferreira, 2000).

\section{Experimento 1: Catação química com diuron + hexazinone e hexazinone}

Aos 4 DAA, notou-se que nenhuma das concentrações avaliadas promoveram níveis aceitáveis de controle das touceiras de capimcolonião, independentemente do herbicida avaliado (Tabela 1). Esses resultados já eram esperados, uma vez que ambos herbicidas apresentam ação sistêmica, e para serem eficientes no controle de plantas daninhas perenes precisam atingir o solo e serem transportados prioritariamente pelo xilema até os cloroplastos (Silva et al., 2007).

$\mathrm{Na}$ avaliação subsequente, realizada aos 10 DAA, observou-se melhora expressiva nos níveis de controle do capim-colonião. Além disso, houve correlação positiva no incremento dos níveis de controle para o aumento na concentração dos herbicidas avaliados. De modo geral, o herbicida hexazinone mostrou-se significativamente mais eficiente que a mistura formulada de diuron + hexazinone. Procópio et al. (2008) também mencionaram a alta eficiência de misturas prontas formuladas com diuron + hexazinone para o controle de touceiras de capim-colonião, evidenciando que as mesmas são dependentes da CTC efetiva do solo, assim como da textura e teor de matéria orgânica. Aos 20 DAA, o controle das touceiras apresentou-se com maior intensidade conforme o aumento na concentração dos herbicidas, tanto para diuron + hexazinone quanto para hexazinone (Tabela 2). 
Tabela 1. Porcentagem de controle de touceiras de capim-colonião ( $P$. maximum) aos 4 e 10 dias após a aplicação (DAA) de diferentes concentrações de diuron + hexazinone e hexazinone. Tapejara/PR, 2012/2013.

\begin{tabular}{|c|c|c|c|c|}
\hline \multirow{3}{*}{ Concentração (\%) } & \multicolumn{4}{|c|}{ Controle 4 DAA (\%) } \\
\hline & \multicolumn{4}{|c|}{ Herbicida } \\
\hline & \multicolumn{2}{|c|}{ diuron + hexazinone } & \multicolumn{2}{|c|}{ hexazinone } \\
\hline 0,0 & 0,0 & Af & 0,0 & Ad \\
\hline 10,0 & 10,7 & $\mathrm{Bd}$ & 23,5 & $\mathrm{Ac}$ \\
\hline 11,7 & 14,7 & $\mathrm{Bb}$ & 25,2 & $\mathrm{Ab}$ \\
\hline 13,3 & 9,5 & $\mathrm{Be}$ & 26,0 & $\mathrm{Aa}$ \\
\hline 15,0 & 13,0 & $\mathrm{Bc}$ & 26,0 & $\mathrm{Aa}$ \\
\hline 16,7 & 20,0 & $\mathrm{Ba}$ & 26,5 & $\mathrm{Aa}$ \\
\hline $\mathrm{F}(\mathrm{C} \times \mathrm{H})$ & & & & \\
\hline $\mathrm{CV}(\%)$ & & & & \\
\hline \multirow{3}{*}{ Concentração (\%) } & \multicolumn{4}{|c|}{ Controle 10 DAA (\%) } \\
\hline & \multicolumn{4}{|c|}{ Herbicida } \\
\hline & \multicolumn{2}{|c|}{ diuron + hexazinone } & \multicolumn{2}{|c|}{ hexazinone } \\
\hline 0,0 & 0,0 & $\mathrm{Ae}$ & 0,0 & Af \\
\hline 10,0 & 30,0 & $\mathrm{Bd}$ & 45,0 & $\mathrm{Ae}$ \\
\hline 11,7 & 40,7 & $\mathrm{Bc}$ & 46,2 & $\mathrm{Ad}$ \\
\hline 13,3 & 42,2 & $\mathrm{Bb}$ & 51,5 & Ac \\
\hline 15,0 & 42,7 & $\mathrm{Bb}$ & 57,5 & $\mathrm{Ab}$ \\
\hline 16,7 & 50,0 & $\mathrm{Ba}$ & 75,5 & $\mathrm{Aa}$ \\
\hline $\mathrm{F}(\mathrm{C} \times \mathrm{H})$ & \multicolumn{4}{|c|}{$539,88^{*}$} \\
\hline $\mathrm{CV}(\%)$ & \multicolumn{4}{|c|}{1,34} \\
\hline
\end{tabular}

Tabela 2. Porcentagem de controle de touceiras de capim-colonião (P. maximum) aos 20 e 30 dias após a aplicação (DAA) de diferentes concentrações de diuron + hexazinone e hexazinone. Tapejara/PR, 2012/2013.

\begin{tabular}{|c|c|c|c|c|}
\hline \multirow{3}{*}{ Concentração (\%) } & \multicolumn{4}{|c|}{ Controle 20 DAA (\%) } \\
\hline & \multicolumn{4}{|c|}{ Herbicida } \\
\hline & \multicolumn{2}{|c|}{ diuron + hexazinone } & \multicolumn{2}{|c|}{ hexazinone } \\
\hline 0,0 & 0,0 & $\mathrm{Ae}$ & 0,0 & Af \\
\hline 10,0 & 72,5 & $\mathrm{Bd}$ & 75,7 & $\mathrm{Ae}$ \\
\hline 11,7 & 80,0 & Ac & 78,5 & $\mathrm{Ad}$ \\
\hline 13,3 & 88,2 & $\mathrm{Ab}$ & 81,2 & $\mathrm{Bc}$ \\
\hline 15,0 & 88,7 & $\mathrm{Ab}$ & 85,7 & $\mathrm{Bb}$ \\
\hline 16,7 & 93,2 & $\mathrm{Ba}$ & 96,5 & $\mathrm{Aa}$ \\
\hline $\mathrm{F}(\mathrm{C} \times \mathrm{H})$ & & & & \\
\hline $\mathrm{CV}(\%)$ & & & & \\
\hline \multirow{3}{*}{ Concentração (\%) } & \multicolumn{4}{|c|}{ Controle 30 DAA (\%) } \\
\hline & \multicolumn{4}{|c|}{ Herbicida } \\
\hline & \multicolumn{2}{|c|}{ diuron + hexazinone } & \multicolumn{2}{|c|}{ hexazinone } \\
\hline 0,0 & 0,0 & $\mathrm{Ad}$ & 0,0 & $\mathrm{Ad}$ \\
\hline 10,0 & 99,0 & $\mathrm{Ab}$ & 97,5 & Ac \\
\hline 11,7 & 100,0 & $\mathrm{Aa}$ & 98,5 & $\mathrm{Ab}$ \\
\hline 13,3 & 100,0 & Aa & 100,0 & Aa \\
\hline 15,0 & 98,7 & Ac & 100,0 & $\mathrm{Aa}$ \\
\hline 16,7 & 100,0 & $\mathrm{Aa}$ & 100,0 & $\mathrm{Aa}$ \\
\hline $\mathrm{F}(\mathrm{C} \times \mathrm{H})$ & \multirow{2}{*}{\multicolumn{4}{|c|}{$\begin{array}{l}6,26^{*} \\
0.45\end{array}$}} \\
\hline $\mathrm{CV}(\%)$ & & & & \\
\hline
\end{tabular}

Médias seguidas de mesma letra minúscula na coluna e maiúscula na linha não diferem entre si pelo teste de Scott-Knott, a 5\% de probabilidade.

Rev. Bras. Herb., v.12, n.3, p.307-317, set./dez. 2013 
Estes resultados podem ser associados ao modo de ação destes herbicidas, que para exercer sua atividade sobre as plantas daninhas, precisam ser introduzidos no solo, o que se dá por meio da incorporação pela umidade presente e também depende da solubilidade do produto (Monquero et al., 2008). Propriedades estas que se interagem com as condições edafoclimáticas, e que irão determinar a disponibilidade do herbicida na solução do solo (Christoffoleti \& López-Ovejero, 2005). Nesse sentido, é importante salientar que sete dias após a aplicação dos herbicidas ocorreu uma precipitação de $15 \mathrm{~mm}$, a qual favoreceu a ação dos herbicidas no solo e na planta.

$\mathrm{Na}$ avaliação aos 30 DAA, notou-se que todos os tratamentos com diuron + hexazinone e hexazinone foram altamente eficientes no controle das touceiras de capim-colonião, com níveis de controle superiores a $98 \%$, independentemente da dose e herbicida avaliado (Tabela 2). Esse fato pode estar associado à eficiência desses herbicidas sobre a espécie estudada (Rodrigues \& Almeida, 2011). Entretanto, Christoffoleti et al. (1988) relataram que a eficiência de controle de touceiras de capim-colonião com hexazinone depende diretamente do estágio de desenvolvimento das plantas. Os autores também constataram excelentes níveis de controle para catação química a partir de $3 \%$ da concentração do produto comercial, sendo utilizado $15 \mathrm{~mL}$ de calda por touceira.

Para o controle de B. decumbens, aos 4 DAA observou-se níveis insuficiente para esta espécie, onde nenhum tratamento herbicida superou 26\% de eficiência (Tabela 3).

Tabela 3. Porcentagem de controle de touceiras de capim-braquiária (B. decumbens) aos 4 e 10 dias após a aplicação (DAA) de diferentes concentrações de diuron + hexazinone e hexazinone. Tapejara/PR, 2012/2013.

\begin{tabular}{|c|c|c|c|c|}
\hline \multirow{3}{*}{ Concentração (\%) } & \multicolumn{4}{|c|}{ Controle 4 DAA (\%) } \\
\hline & \multicolumn{4}{|c|}{ Herbicida } \\
\hline & \multicolumn{2}{|c|}{ diuron + hexazinone } & \multicolumn{2}{|c|}{ hexazinone } \\
\hline 0,0 & 0,0 & Af & 0,0 & Af \\
\hline 10,0 & 10,0 & $\mathrm{Be}$ & 12,0 & $\mathrm{Ad}$ \\
\hline 11,7 & 11,7 & Ad & 12,0 & $\mathrm{Ad}$ \\
\hline 13,3 & 15,0 & Ac & 15,0 & Ac \\
\hline 15,0 & 25,0 & $\mathrm{Ab}$ & 17,3 & $\mathrm{Bb}$ \\
\hline 16,7 & 26,0 & $\mathrm{Aa}$ & 19,0 & $\mathrm{Ba}$ \\
\hline $\mathrm{F}(\mathrm{C} \times \mathrm{H})$ & & & & \\
\hline $\mathrm{CV}(\%)$ & & & & \\
\hline \multirow{3}{*}{ Concentração (\%) } & \multicolumn{4}{|c|}{ Controle 10 DAA (\%) } \\
\hline & \multicolumn{4}{|c|}{ Herbicida } \\
\hline & \multicolumn{2}{|c|}{ diuron + hexazinone } & \multicolumn{2}{|c|}{ hexazinone } \\
\hline 0,0 & 0,0 & $\mathrm{Ae}$ & 0,0 & Af \\
\hline 10,0 & 59,0 & $\mathrm{Ad}$ & 55,2 & $\mathrm{Be}$ \\
\hline 11,7 & 65,0 & $\mathrm{Ab}$ & 57,5 & $\mathrm{Bd}$ \\
\hline 13,3 & 61,5 & $\mathrm{Bc}$ & 63,5 & Ac \\
\hline 15,0 & 59,0 & $\mathrm{Bd}$ & 66,0 & $\mathrm{Ab}$ \\
\hline 16,7 & 72,0 & $\mathrm{Ba}$ & 75,0 & $\mathrm{Aa}$ \\
\hline $\mathrm{F}(\mathrm{C} \times \mathrm{H})$ & \multicolumn{4}{|c|}{$66,25^{*}$} \\
\hline $\mathrm{CV}(\%)$ & \multicolumn{4}{|c|}{0,81} \\
\hline
\end{tabular}

Entretanto, observa-se que houve herbicidas. A mistura formulada de diuron + incremento significativo dos níveis de controle hexazinone mostrou-se superior ao hexazinone com o aumento da concentração de ambos os isolado, principalmente nas maiores 
concentrações. Aos 10 DAA, também foi constatado incremento significativo no controle de capim-braquiária, observando-se ampliação das necroses na área dos tecidos foliares, o que caracterizou aumento progressivo do controle das touceiras, a partir da concentração de $10 \%$. Todas as plantas apresentaram sintomas de amarelecimento com aspecto de queima nas folhas, sendo esses sintomas de danos também foram descritos por Blanco et al. (1980).

A partir dos 20 DAA, a semelhança entre os resultados de controle dos herbicidas foi grande, sendo caracterizados a partir da menor concentração níveis de controle satisfatórios, ou seja, identificados como superiores a 83,5\% (Tabela 4). Entretanto, observou-se superioridade no controle para as maiores concentrações dos herbicidas $(15,0$ e $16,7 \%$ ), com níveis de eficiência superiores a $94,2 \%$. Os resultados de controle aos 30 DAA demonstraram a alta eficiência de hexazinone e diuron+hexazinone no controle de capimbraquiária, onde foi constatada a partir da concentração de $10 \%$, a morte total das touceiras.

Para os resultados com diuron + hexazinone e hexazinone, pode-se inferir que recomendações com concentrações ainda menores destes herbicidas possam ser estudadas, uma vez que a dose mínima testada promoveu a completa eliminação das touceiras de capim-braquiária. Além disso, de forma geral, observou-se uma tendência de maior sensibilidade do capim-braquiária, quando comparado ao capim-colonião. Christoffoleti et al. (1995), mencionaram a ocorrência de controle satisfatório de touceira de capimcolonião com solução em concentração de $1 \%$ do produto comercial de diuron + hexazinone, utilizando de 70 a $100 \mathrm{~mL}$ por plantas no estádio de pré-florescimento, em operação de catação química.

Tabela 4. Porcentagem de controle de touceiras de capim-braquiária (B. decumbens) aos 20 e 30 dias após a aplicação (DAA) de diferentes concentrações de diuron + hexazinone e hexazinone. Tapejara/PR, 2012/2013.

\begin{tabular}{|c|c|c|}
\hline \multirow{3}{*}{ Concentração (\%) } & \multicolumn{2}{|c|}{ Controle 20 DAA (\%) } \\
\hline & \multicolumn{2}{|c|}{ Herbicida } \\
\hline & diuron + hexazinone & hexazinone \\
\hline 0,0 & $0,0 \quad \mathrm{Ae}$ & 0,0 Af \\
\hline 10,0 & 85,5 Ad & 83,5 \\
\hline 11,7 & $86,0 \quad \mathrm{Ad}$ & 85,5 \\
\hline 13,3 & 87,2 Ac & 87,0 \\
\hline 15,0 & $96,2 \mathrm{Ab}$ & 94,2 \\
\hline 16,7 & $98,0 \quad$ Aa & 97,5 \\
\hline $\mathrm{F}(\mathrm{C} \times \mathrm{H})$ & & \\
\hline CV $(\%)$ & & \\
\hline \multirow{3}{*}{ Concentração (\%) } & \multicolumn{2}{|c|}{ Controle 30 DAA (\%) } \\
\hline & \multicolumn{2}{|c|}{ Herbicida } \\
\hline & diuron + hexazinone & hexazinone \\
\hline 0,0 & 0,0 & 0,0 \\
\hline 10,0 & 100,0 & 100,0 \\
\hline 11,7 & 100,0 & 100,0 \\
\hline 13,3 & 100,0 & 100,0 \\
\hline 15,0 & 100,0 & 100,0 \\
\hline 16,7 & 100,0 & 100,0 \\
\hline
\end{tabular}

Médias seguidas de mesma letra minúscula na coluna e maiúscula na linha não diferem entre si pelo teste de Scott-Knott, a $5 \%$ de probabilidade.

Não foram observados novos rebrote das plantas de capim-colonião e capimbraquiária aos 110 DAA, mesmo para a menor concentração dos herbicidas (10\%) (Dados não demonstrados). Nesse sentido, os resultados comprovam a eficácia dos tratamentos em 
eliminar as touceiras perenizadas de ambas as espécies de plantas daninhas em canaviais utilizando a técnica de catação química dirigida.

\section{Experimento 2: Catação química com isoxaflutole}

Para o segundo experimento, onde se avaliou $o$ herbicida isoxaflutole como alternativa para a catação química de touceiras de capim-colonião e capim-braquiária, houve ajuste significativo dos dados ao modelo de regressão linear, onde caracterizou-se a correlação positiva entre $o$ aumento na

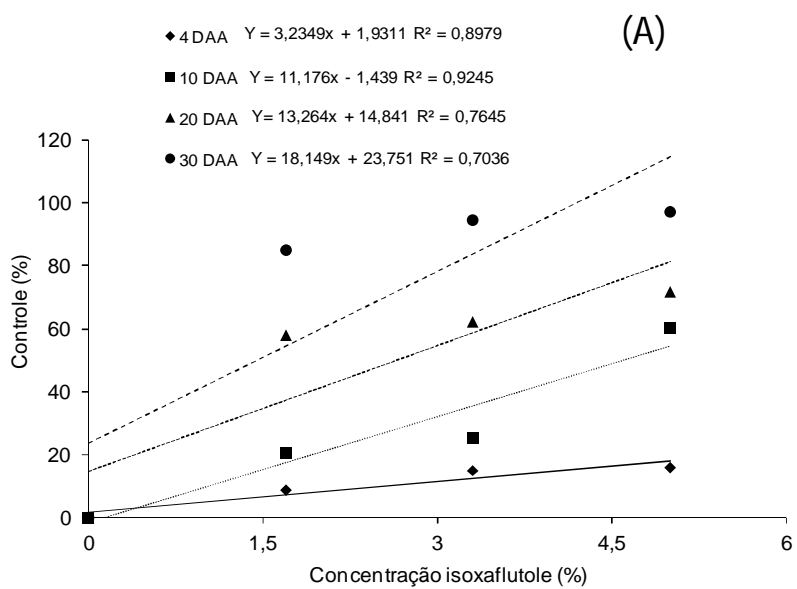

concentração do isoxaflutole e a porcentagem de eficiência de controle das plantas daninhas avaliadas (Figura 2).

Para o capim-colonião, foi caracterizado que seria necessária uma concentração mínima de 4,2\% de isoxaflutole para promover a eliminação completa das touceiras dessa planta daninha aos 30 DAA, segundo ajuste dos dados originais ao modelo de regressão linear (Figura 2A). Nas avaliações anteriores (4, 10 e 20 DAA) não se observou níveis eficazes de controle da referida espécie para o intervalo de concentração de isoxaflutole avaliado.

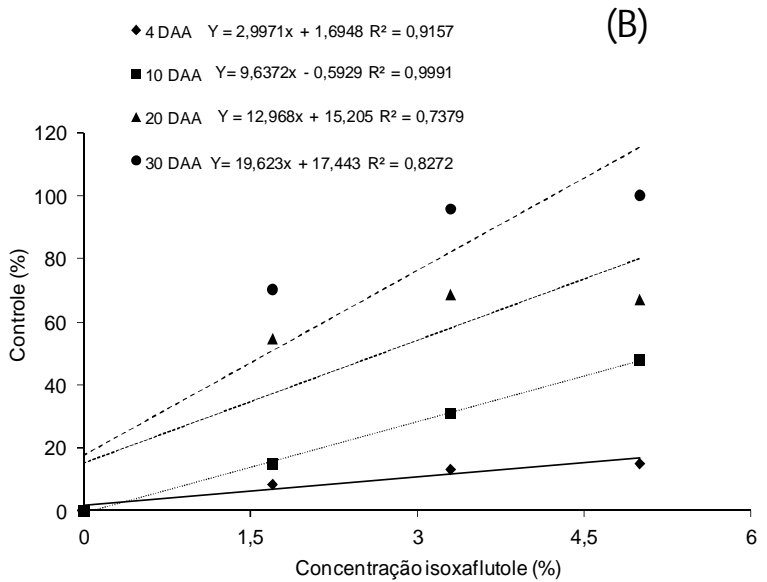

Figura 2. Porcentagem de controle de capim-colonião ( $P$. maximum) (A) e capim-braquiária ( $B$. decumbens) (B) aos 4, 10, 20 e 30 dias após a aplicação de isoxaflutole. Tapejara/PR, 2012/2013.

A mesma dinâmica foi observada para a espécie capim-braquiária (Figura 2B), onde nas avaliações de 4, 10 e 20 DAA não houve eficácia do isoxaflutole para concentrações avaliadas, segundo o ajuste dos dados ao modelo de regressão linear. Já aos 30 DAA, de maneira similar ao descrito para o capimcolonião, seria necessária uma concentração mínima de $4,2 \%$ para se obter máxima eficiência na eliminação das touceiras de capim-braquiária.

$\mathrm{Na}$ Figura 4, encontram-se as curvas ajustadas da porcentagem de rebrote de capim- colonião e capim-braquiária aos 110 DAA. Para o capim-colonião foi necessária uma concentração mínima de $4,8 \%$ de isoxaflutole para anular o rebrote das touceiras, enquanto que para o capim-braquiária a concentração mínima para não ocorrer rebrote foi de 4,2\%. Portanto, observou-se que foi necessária uma maior concentração de isoxaflutole para garantir eliminação total das touceiras de capim-colonião, em relação às de capimbraquiária. 


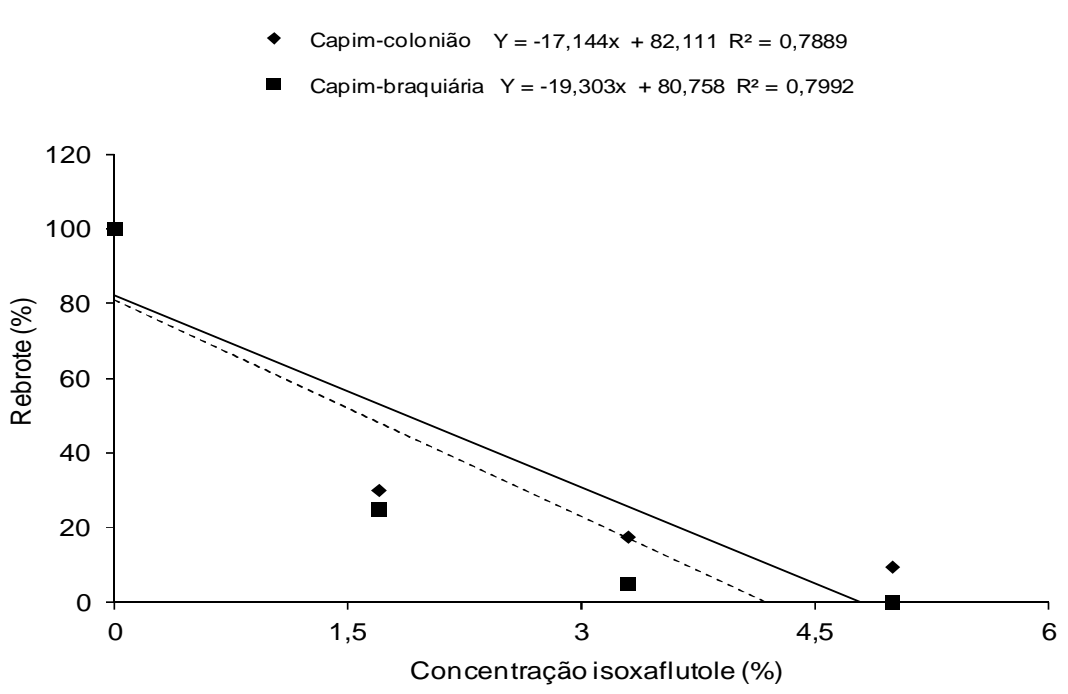

Figura 4. Porcentagem de rebrote de capim-colonião ( $P$. maximum) e capim-braquiária $(B$. decumbens) aos 110 dias após a aplicação de isoxaflutole. Tapejara/PR, 2012/2013.

Onde se utilizou a maior dose de isoxaflutole observou-se que algumas touceiras de cana-de-açúcar apresentaram sintomas de branqueamento das folhas novas.

Apesar da escassez de informações científicas sobre catação química de espécies de plantas remanescentes na cultura da canade-açúcar em termos de literatura nacional e internacional, Ferreira et al. (2010) relataram que já existirem parcerias entre empresa de agrotóxicos e tecnologia de aplicação, visando desenvolver equipamentos para realizar operação de "catação química tratorizada". Nesses projetos a aplicação do herbicida ocorre somente onde se observam plantas daninhas, utilizando um sistema de saídas independentes para cada ponta de pulverização (bico) em sistema de pingentes, a qual é acionada pelo operador por meio de um comando eletrônico, aplicando o herbicida apenas no local onde ocorre a infestação.

\section{Conclusão}

Os herbicidas diuron + hexazinone e hexazinone utilizados na modalidade de catação química foram eficientes no controle de Panicum maximum e Brachiaria decumbens, a partir da concentração de $10 \%$ da calda de aplicação dos produtos comerciais.

Para o isoxaflutole, foi necessário a concentração mínima de 4,8\% e 4,2\% da calda de aplicação do produto comercial, para se obter a máxima eficiência de controle da operação de catação química das rebrotas de $P$. maximum e $B$. decumbens, respectivamente.

\section{Referências}

BHOWMIK, P.C.; NEAL, J.C. Turfgrass weed control strategies. In: ANNUAL MEETING O F THE NORTHEASTERN WEED SCIENCE SOCIETY, 49, 1995, Raleigh. Proceedings... Raleigh: NWSC, 1995. p.154-155.

BLANCO, H.G. et al. Fitotoxicidade em cana de açúcar causada pela interação de inseticida e herbicida residual. O Biológico, v.46, n.10, p.235-240, 1980.

CHRISTOFFOLETI, P. J. et al. Controle de capim-colonião (Panicum maximum) em condições de pós-emergência tardia na cultura da cana-de-açúcar (Saccharum sp.) através de herbicidas. In: CONGRESSO BRASILEIRO DA CIÊNCIA DAS PLANTAS DANINHAS, 20., 1995, Florianópolis. Resumos... Londrina: 
Sociedade Brasileira da Ciência das Plantas Daninhas, 1995. p.194-195.

CHRISTOFFOLETI, P. J.; LÓPES-OVEJERO, R. F. Dinâmica dos herbicidas aplicados ao solo na cultura da cana-de-açúcar. Piracicaba: BASF, 2005. 49 p.

CHRISTOFFOLETI, P. J.; SILVEIRA, R.B.; DELBBEN, L.V. Estudo da eficiência, seletividade, equipamentos e adição de adjuvantes no controle do Panicum maximum (capim-colonião) através de hexazinone aplicado em condição de pós-emergência na cultura da cana-de-açúcar (Saccharum spp). In: CONGRESSO BRASILEIRO DE HERBICIDAS E PLANTAS DANINHAS, 17. 1988, Piracicaba. Resumos... Londrina: Sociedade Brasileira da Ciência das Plantas Daninhas, 1988. p.338-340.

CHRISTOFFOLETI, P.J. et al. Manejo de plantas daninhas na cultura da cana-deaçúcar: novas moléculas herbicidas. 2011. Disponível em: <http//:www.ppifar.org/Anais\%20Jacob\%.com.br>. Acesso em: 25 maio. 2013.

DINARDO-MIRANDA, L.L. et al. Cana-deaçúcar. Campinas: Instituto Agronômico, 2008.

EMBRAPA. Centro Nacional de Pesquisa de Solos. Sistema Brasileiro de Classificação de Solos, Rio de Janeiro. Embrapa Solos, 2006. $306 \mathrm{p}$.

FERREIRA, D.F. SISVAR: Sistema para análise de variância para dados balanceados. Lavras: UFLA, 79p. 2000.

FERREIRA, E.A. et al. Manejo de plantas daninha em cana-crua. Planta Daninha, v. 28, n. 4, p. 915-925, 2010.

GALLI, A.J.B.; MONTEZUMA, M.C. Alguns aspectos da utilização do herbicida glifosato na agricultura. Monsanto do Brasil Ltda: ACADCOM Gráfica e Editora Ltda, 2005. 67 p.
KUVA, M.A. et al. Períodos de interferência das plantas daninhas na cultura da cana-deaçúcar. II - capim-brachiaria (Brachiaria decumbens). Planta Daninha, v.19, n.3, p.323330, 2001.

KUVA, M.A. et al. Períodos de interferência das plantas daninhas na cultura da canadeaçúcar. III - capim-brachiaria (Brachiaria decumbens) e capim-colonião (Panicum maximum). Planta Daninha, v.21, n.1, p.3744, 2003.

LORENZI, H. Plantas daninhas do Brasil: terrestres, aquáticas, parasitas e tóxicas. 4.ed. Nova Odessa: Plantarum, 2008. 640p.

MASCARENHAS, M.T.H. et al. Eficácia do halosulfuron no controle de tiririca (Cyperus rotundus) na cultura da cana-de-açúcar. Planta Daninha, v.13, n.2, p.69-80, 1995.

MONQUERO, P.A. et al. Mobilidade e persistência de herbicidas aplicados em préemergência em diferentes tipos de solo. Planta Daninha, v.26, n.1, p.411-417, 2008.

PALLET, K.E. et al. The mode of action of isoxaflutole. I. Physiological effects, metabolism, and selectivity. Pesticide Biochemistry Physiology, v.62, n.1, p.113124, 1998.

PITELLI, R.A. Interferência de plantas daninhas em culturas agrícolas. Informe Agropecuário, v.11, n.129, p.16-27, 1985.

PROCÓPIO, S.O.; SILVA, A.A.; VARGAS, L. Manejo e controle de plantas daninhas em cana-de-açúcar. In: VARGAS, L.; ROMAN, E.S. (Eds.) Manual de manejo e controle de plantas daninhas. 2.ed. Passo Fundo: EMBRAPA Trigo, 2008. p. 477-531.

RODRIGUES, B.N.; ALMEIDA, F.R. Guia de herbicidas. $5^{\mathrm{a}}$ ed, Londrina: Edição dos Autores, 2011. 697p.

RODRIGUES, E.B.; ABI SAAB, O.J.B.; GANDOLFO, M.O. Cana-de-açúcar: Avaliação da taxa de aplicação e deposição do 
herbicida glifosato. Revista Brasileira de Engenharia Agrícola e Ambiental, v.15, n.1, p.90-95, 2011.

SILVA, A.A. et al. Herbicidas: classificação e mecanismo de ação. In: SILVA, A.A.; SILVA, J.F. Tópicos em manejo de plantas daninhas. Viçosa: UFV, 2007. p.83-148.

SOCIEDADE BRASILEIRA DA CIÊNCIA DAS PLANTAS DANINHAS. Procedimentos para instalação, avaliação e análise de experimentos com herbicidas. Londrina: SBCPD, 1995. 42p. 